\title{
On the Importance of the Thiazole Nitrogen in Epothilones: Semisynthesis and Microtubule-Binding Affinity of Deaza-Epothilone C
}

\author{
Adriana Edenharter ${ }^{1}$, Lucie Ryckewaert ${ }^{1}$, Daniela Cintulová ${ }^{1}$, Juan Estévez-Gallego ${ }^{2}$, \\ José Fernando Díaz ${ }^{2}$ and Karl-Heinz Altmann 1,*(D) \\ 1 ETH Zürich, Department of Chemistry and Applied Biosciences, Institute of Pharmaceutical Sciences, \\ CH-8093 Zürich, Switzerland; adriana.edenharter@gmx.com (A.E.); lucie.ryckewaert@yahoo.com (L.R.); \\ daniela.cintulova@tuwien.ac.at (D.C.) \\ 2 Centro de Investigaciones Biológicas Margarita Salas, Consejo Superior de Investigaciones Científicas, \\ 28040 Madrid, Spain; jeg@cib.csic.es (J.E.-G.); fer@cib.csic.es (J.F.D.) \\ * Correspondence: karl-heinz.altmann@pharma.ethz.ch
}

Received: 18 April 2020; Accepted: 21 May 2020; Published: 23 May 2020

check for updates

\begin{abstract}
Deaza-epothilone $\mathrm{C}$, which incorporates a thiophene moiety in place of the thiazole heterocycle in the natural epothilone side chain, has been prepared by semisynthesis from epothilone $\mathrm{A}$, in order to assess the contribution of the thiazole nitrogen to microtubule binding. The synthesis was based on the esterification of a known epothilone A-derived carboxylic acid fragment and a fully synthetic alcohol building block incorporating the modified side chain segment and subsequent ring-closure by ring-closing olefin metathesis. The latter proceeded with unfavorable selectivity and in low yield. Distinct differences in chemical behavior were unveiled between the thiophene-derived advanced intermediates and what has been reported for the corresponding thiazole-based congeners. Compared to natural epothilone $\mathrm{C}$, the free energy of binding of deaza-epothilone $\mathrm{C}$ to microtubules was reduced by ca. $1 \mathrm{kcal} / \mathrm{mol}$ or less, thus indicating a distinct but non-decisive role of the thiazole nitrogen in the interaction of epothilones with the tubulin/microtubule system. In contrast to natural epothilone $C$, deaza-epothilone $C$ was devoid of antiproliferative activity in vitro up to a concentration of $10 \mu \mathrm{M}$, presumably due to an insufficient stability in the cell culture medium.
\end{abstract}

Keywords: binding affinity; epothilones; deaza-epothilone; microtubules; structure-activity relationship; thiophene

\section{Introduction}

Epothilones A and B (Epo A and B) (Figure 1) are 16-membered, polyketide-derived macrolides that were discovered in 1987 by Reichenbach et al. in the context of a screening for new antifungal agents from the soil-dwelling myxobacterium Sorangium cellulosum Soce 90 [1,2]. A number of closely related, but less prevalent polyketides, like epothilones C (Epo C) and D (Epo D) were later identified in larger scale fermentations of S. cellulosum [3].
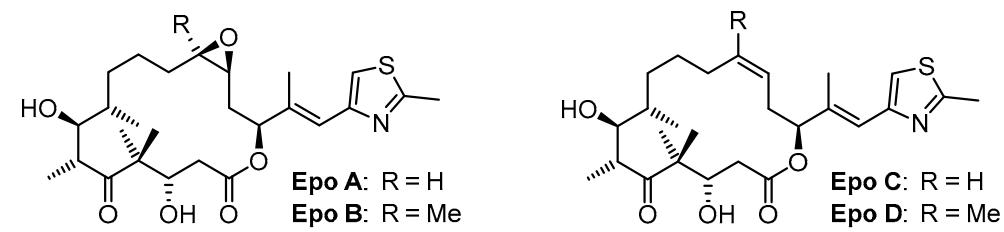

Figure 1. Molecular structures of natural epothilones A-D (Epo A-D). 
Epo A and B were subsequently found to be highly cytotoxic in the 60-cell line panel of the National Cancer Institute, although the mechanistic underpinnings of this effect remained unknown at the time [4]. Interest in epothilones then surged in 1995, when Bollag et al. demonstrated that Epo A and $\mathbf{B}$ were new microtubule-stabilizing agents and, thus, inhibited cell proliferation by a taxol-like mechanism [5]. At the time of discovery of their mode of action, Epo $\mathbf{A}$ and $\mathbf{B}$ were the only non-taxane compound class known to stabilize microtubules, but in contrast to taxol they retained almost full activity (i.e., $\mathrm{IC}_{50}$ values in the $\mathrm{nM}$ range) against multidrug-resistant cancer cells expressing the P-glycoprotein efflux pump or harboring tubulin mutations [6,7].

Numerous total syntheses of natural epothilones have been reported in the literature, and these efforts have been reviewed extensively [8-13]. Based on the chemistry developed in the context of the total synthesis work, hundreds of synthetic analogues of epothilones have been prepared for structure-activity relationship (SAR) studies and with the objective to deliver compounds with an improved overall pharmacological profile $[14,15]$. In addition, semisynthetic approaches have been pursued to explore the epothilone-like structural space, in particular by Höfle and co-workers. (This work is summarized in ref. [16]). The most important semisynthetic epothilone derivative is the Epo B lactam ixabepilone, which is approved by the FDA (under the tradename Ixempra ${ }^{\circledR}$ ) for the treatment of metastatic or locally advanced breast cancer [17]. At least eight additional epothilone-type agents have been advanced to clinical trials in oncology, including the natural product Epo A [14,15], and Epo D has also been investigated in Phase I clinical trials for Alzheimer's disease [18]. The development of most of these compounds has been discontinued (including the development of Epo D for Alzheimer's disease), but an analog termed utidelone (or UTD1) is currently being studied in Phase III clinical trials against breast cancer (in combination with capecitabine) [19].

While numerous side chain-modified epothilone analogs have been investigated as part of comprehensive SAR studies $[15,16]$, a specific question that has been addressed only indirectly relates to the importance of the $\mathrm{N}$-atom in the thiazole ring for microtubule binding and cellular potency. Thus, Nicolaou and co-workers have shown that among the three possible pyridyl-Epo B variants (Figure 2), the isomer with the $\mathrm{N}$-atom in the position ortho to the vinyl linker between the pyridine ring and the macrolactone core (i.e., $\boldsymbol{o}$-Pyr-Epo B) is the most potent with regard to both the promotion of tubulin polymerization and the inhibition of cancer cell growth in vitro [20]. At the same time, the meta and para isomers ( $m$-Pyr-Epo B and $p$-Pyr-Epo B, respectively) still retained a significant tubulin-polymerizing capacity, which reflects the ability of a compound to stabilize microtubules.
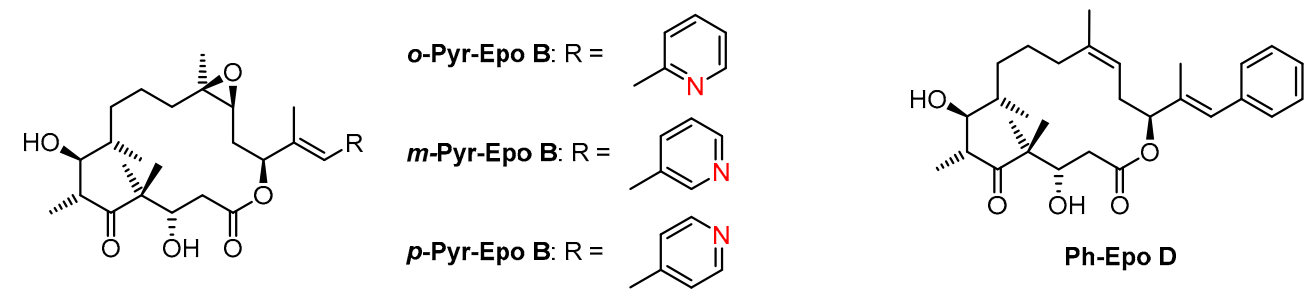

Figure 2. Molecular structures of the three possible pyridyl-Epo B variants and of phenyl-Epo D.

Nicolaou's data were in line with the results of an earlier study by Danishefsky and co-workers who had reported the phenyl-based Epo D analog Ph-Epo D (Figure 2) to be a potent inducer of tubulin polymerization, albeit to a lower extent than the natural product Epo $\mathbf{D}$ itself [21]. These data suggested that the presence of a heterocyclic $N$-atom next to the vinyl linker moiety in epothilone analogs is required for maximum induction of tubulin assembly and, consequently, for the inhibition of cancer cell proliferation. However, neither of the above studies included a quantitative assessment of the microtubule-binding affinity of the analogs investigated. In this context, it needs to be recognized that the assessment of tubulin polymerization induction is useful for the unequivocal identification of compounds with poor tubulin assembly properties, but is less suited for the high-resolution quantitative differentiation between potent assembly inducers. In our own work, we have demonstrated that the 
microtubule-binding affinities of quinoline-based epothilone analogs (Figure 3) [22] that incorporate the side chain N-atom in the "natural" position (i.e., $m$-Quin-Epo B and $m$-Quin-Epo D) are ca. one order of magnitude higher than those of the corresponding regioisomers $p$-Quin-Epo $B$ and $p$-Quin-Epo $D$, respectively ( $\mathrm{K}_{\mathrm{b}}$ 's of $92 \times 10^{7}$ and $88 \times 10^{7}$ for $m$-Quin-Epo $\mathbf{B}$ and $m$-Quin-Epo $\mathrm{D}$, respectively, vs. $6.9 \times 10^{7}$ and $6.1 \times 10^{7}$ for $p$-Quin-Epo B and $p$-Quin-Epo D). Quite intriguingly, and for reasons not understood, the difference in the microtubule-binding affinity between $m$-Quin-Epo $\mathbf{D}$ and $p$-Quin-Epo $\mathrm{D}$ translates into a corresponding difference in the cellular activity, while the epoxides $m$-Quin-Epo B and $p$-Quin-Epo B are virtually equipotent (and highly active).

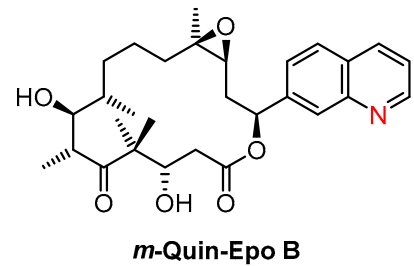

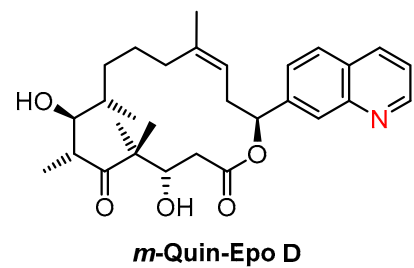

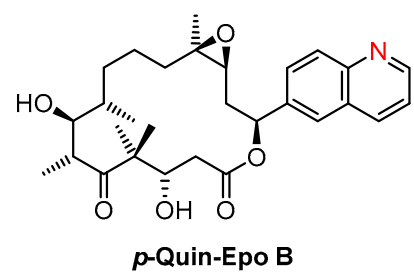

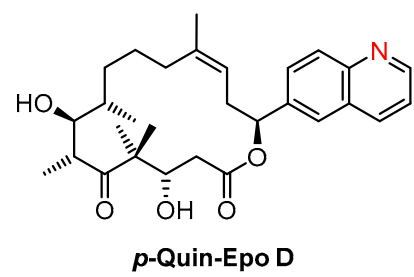

Figure 3. Molecular structures of quinoline-derived epothilone analogs.

While our data for quinoline-based epothilone analogs seem to re-enforce the conclusions derived from the earlier studies by Nicolaou and Danishefsky on pyridyl- and phenyl-based epothilone analogs, respectively, they need to be interpreted with some care, in light of the significant overall modification of the side chain vs. natural epothilones. Finally, the recent $X$-ray crystal structure of a tubulin-Epo A complex [23] invokes a hydrogen bond between the thiazole nitrogen and the side chain hydroxy group of $\beta$ Thr297. Overall, the available experimental data suggest that the presence of a properly positioned heterocyclic $\mathrm{N}$-atom in side chain-modified epothilone analogs is required, in order to maximize interactions with the tubulin/microtubule system. At the same time, the magnitude of the effect associated with the simple removal of this nitrogen from the natural side chain, quite surprisingly, has never been assessed. We have thus been interested for some time in the synthesis of a thiophene-containing analog of a natural epothilone and the determination of its microtubule-binding affinity in comparison with the natural parent structure. In this paper, we describe the results of these efforts.

\section{Materials and Methods}

Detailed protocols for the synthesis of new compounds and the associated analytical data can be found in the Supplementary Materials.

\section{Results and Discussion}

\subsection{Synthesis of Deaza-Epo C (5)}

The initial synthetic target of our work was deaza-Epo A (1), which we planned to access from ketone 2 by means of the Wittig or Horner-Woodsworth-Emmons (HWE) reaction (Scheme 1). Ketone 2 can be accessed from Epo A by TMS-protection and ozonolysis [24]; and its conversion into TMS-protected 3 via the transformation of the ketone moiety into the corresponding vinyl boronic acid, followed by iodination and Stille coupling, had been described earlier by Höfle and co-workers [25]. 
However, no experimental protocols for this reaction sequence are provided in ref. [25], and no yields are reported for the iodination and Stille coupling steps. On the other hand, we had been successful ourselves in the elaboration of ketone 2 into epothilone A analogs bearing modified thiazole, pyrimidine or pyridine moieties in place of the natural thiazole heterocycle by means of HWE chemistry (Hauenstein \& Altmann, unpublished experiments; see also refs. [26,27]). Unfortunately, the attempted HWE coupling of $\mathbf{2}$ with phosphonate 4 did not yield any of the desired olefin (Scheme 1).

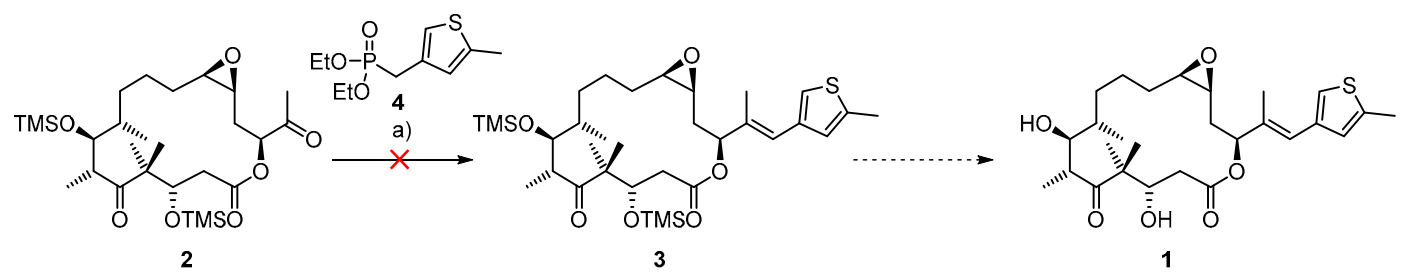

Scheme 1. Reagents and conditions: a) $n \mathrm{BuLi},-78^{\circ} \mathrm{C}$ to RT, $0 \%$.

In light of a previous report by Höfle and co-workers, who had been unable of convert 2 into phenyl-Epo A or to reconstruct Epo A from 2 by a variety of olefination methods [24], we did not further pursue the direct elaboration of 2 into 1 . Instead, we turned our attention to a different aspect of the chemistry of Epo A that had been unveiled by Höfle's work on semisynthetic epothilone derivatives and that involves the targeted removal of the C13-C15 segment of the macrocycle to generate acid 8 [28] (Scheme 2). The latter was then to be esterified with alcohol 7, and the resulting diene would be cyclized by ring-closing olefin metathesis (RCM) in analogy to previous work on the total synthesis of Epo A [29-31]. Deprotection would then yield deaza-Epo C (5).

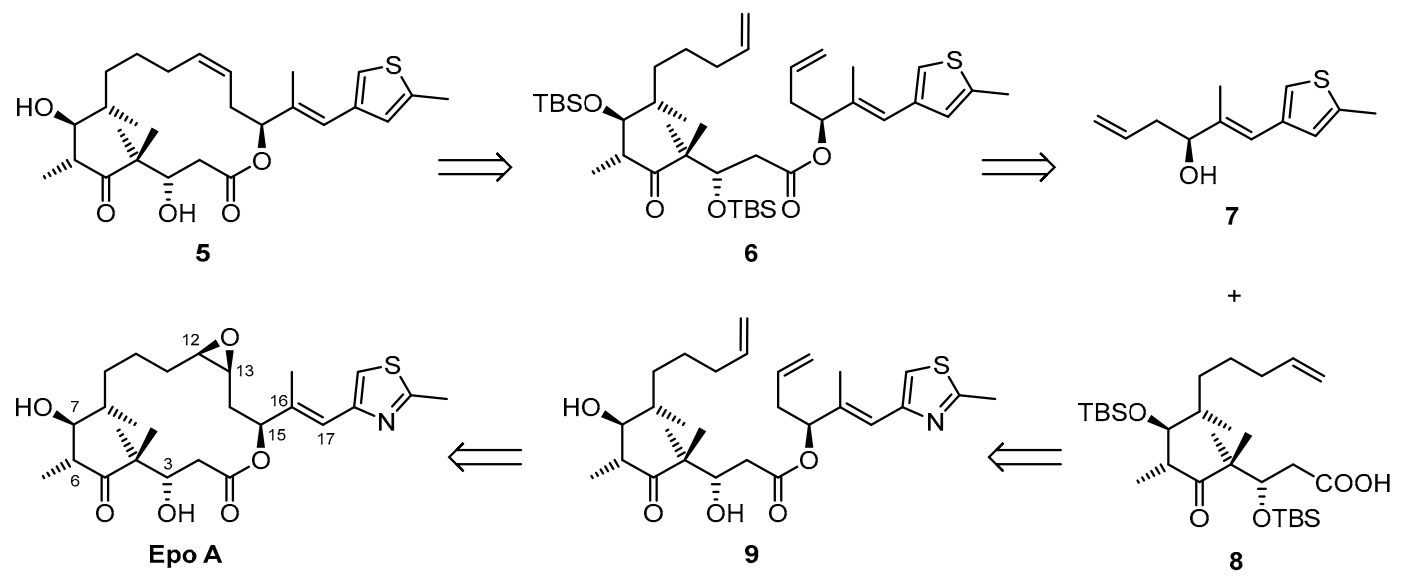

Scheme 2. Retrosynthesis of deaza-Epo C (5).

When elaborating this strategy, we were cognizant of the fact that the conversion of the Epo C analog 5 into 1 might be impaired by the competing epoxidation of the $\mathrm{C} 16-\mathrm{C} 17$ double bond, which is more nucleophilic than in Epo C, and/or oxidation at sulfur [32]. At the same time, we also felt that our question about the effects of the removal of the thiazole nitrogen could be addressed by comparing the microtubule-binding affinity of $\mathbf{5}$ with that of Epo C, as the latter had also been reported to be a potent inducer of tubulin polymerization [33] (although no microtubule binding data for the compound exist in the literature).

In the forward direction, the synthesis of acid 8 commenced with the deoxygenation of Epo A with 3-methylbenzo[d]thiazole-2(3H)-selenone (10), prepared according to Calo and co-workers by refluxing methylbenzothiazolium iodide and elemental selenium in pyridine [34] (Scheme 3). 


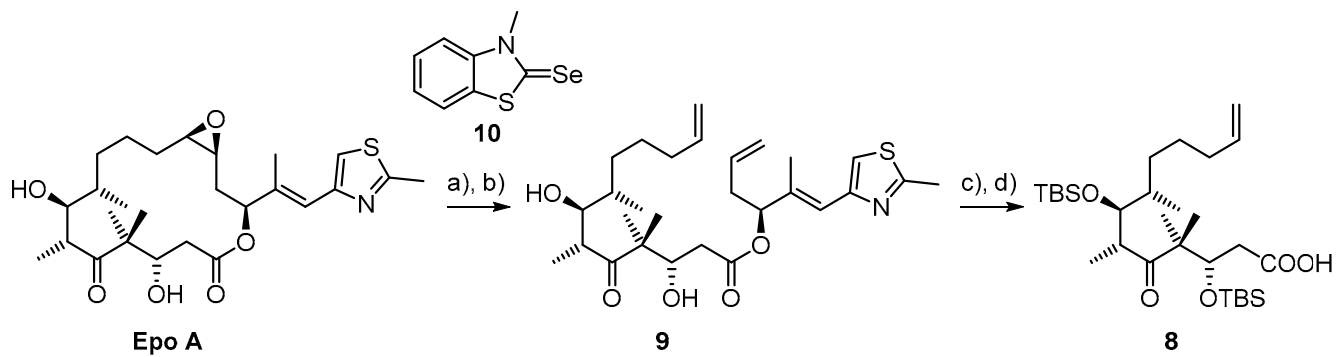

Scheme 3. Reagents and conditions: a) 10, TFA, DCM, 6 h, RT, 43\%; b) Hoveyda-Grubbs-II cat., DCM, $20 \mathrm{~h}, \mathrm{RT}, 61 \%$; c) i) 2,6-lutidine, DCM, $10 \mathrm{~min}$, RT, ii) TBSOTf, $5 \mathrm{~min}, 110{ }^{\circ} \mathrm{C}$, microwave; d) $\mathrm{LiOH}, \mathrm{H}_{2} \mathrm{O}$, $i \mathrm{PrOH}, 5 \mathrm{~min}, 150{ }^{\circ} \mathrm{C}$, microwave, $61 \%$ over two steps.

The deoxygenation reaction gave Epo $\mathrm{C}$ in highly variable yields, due to incomplete conversion and the formation of an unknown side product that was difficult to remove. It was found eventually, however, that the subsequent ring-opening reaction proceeded equally well without the prior removal of this impurity, thus obviating the need for the tedious purification of the intermediate Epo C. The ring-opening of the macrocycle with ethylene in the presence of the Grubbs-Hoveyda II catalyst furnished diene 9 (as described [28]), which was converted into acid 8 by sequential treatment with TBSOTf and $\mathrm{LiOH}$ at elevated temperature under microwave conditions in $61 \%$ overall yield.

The synthesis of alcohol 7 started from 3-thienylmethanol (11), which was TBS-protected; deprotonation of TBS-ether 12 with $n \mathrm{BuLi}$ (1.1 equiv) and reaction with a two-fold excess of MeI then provided TBS-ether 13 in 62\% yield (Scheme 4). The deprotection of 13 with TBAF, followed by oxidation of the ensuing free alcohol under Swern conditions, afforded the desired aldehyde $\mathbf{1 5}$ in $71 \%$ overall yield. The Wittig reaction of 15 with 16 then delivered homologated aldehyde $\mathbf{1 7}$ (71\% yield).

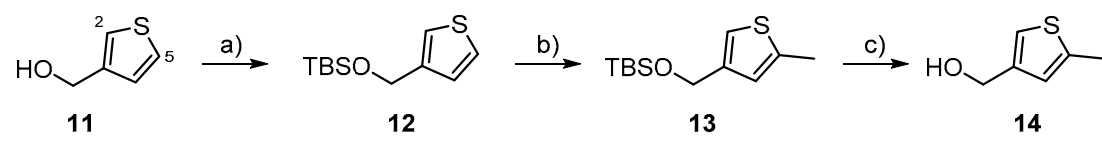<smiles>[3H]C(O)C(C)/C=C(\C)c1csc(C)c1</smiles>

Scheme 4. Reagents and conditions: a) TBSCl, imidazole, DMF, $5 \mathrm{~h}, 45^{\circ} \mathrm{C}$, quant.; b) $n \mathrm{BuLi}, \mathrm{MeI}, \mathrm{THF}$, $18 \mathrm{~h},-35^{\circ} \mathrm{C}$ to RT, $62 \%$; c) TBAF, THF, $3 \mathrm{~h}$, RT; d) oxalyl chloride, DMSO, DCM, NEt $3,2 \mathrm{~h},-78^{\circ} \mathrm{C}$ to RT, $71 \%$ (2 steps); e) 16, benzene, $23 \mathrm{~h}, 103{ }^{\circ} \mathrm{C}, 71 \%$; f) 18, dibutylboron triflate, DIPEA, DCM, $4 \mathrm{~h},-78{ }^{\circ} \mathrm{C}$ to $0{ }^{\circ} \mathrm{C}, 51 \%$; g) TBSCl, imidazole, DMF, $4.5 \mathrm{~h}, 45^{\circ} \mathrm{C}, 79 \%$; h) DIBAL-H, DCM, $2 \mathrm{~h},-78{ }^{\circ} \mathrm{C}, 80 \%$; i) 22, NaHMDS, THF, $2 \mathrm{~h},-78{ }^{\circ} \mathrm{C}, 88 \%$; j) TBAF, THF, $5 \mathrm{~h}, 0^{\circ} \mathrm{C}$ to RT, $94 \%$. 
The reaction of $\mathbf{1 7}$ with the dibutylboron enolate of acetylsultam 18, obtained by the successive treatment of the latter with dibutylboron triflate and DIPEA [22,35], proceeded with only moderate selectivity, to afford a ca. 2:1 mixture of aldol products, in favor of the desired isomer 19 [36]. Preparing the dibutylboron triflate in situ from triethylborane and trifluoromethanesulfonic acid did not lead to an improved $d r$. Although tedious, isomer separation was possible by column chromatography, and 19 was finally obtained as a single isomer in 51\% yield; the latter was then protected as its TBS-ether $\mathbf{2 0}$. The reductive cleavage of the auxiliary with DIBAL-H, followed by Julia-Kocienski olefination of the ensuing aldehyde $\mathbf{2 1}$ with sulfone $\mathbf{2 2}$ and subsequent TBS-deprotection, gave homoallylic alcohol 7 in ca. $8.5 \%$ overall yield for the 10-step sequence from 3-thienylmethanol (11). The attempted Wittig olefination of aldehyde 21 with methyltriphenylphosphonium bromide in combination with various bases had been found previously to induce the elimination of TBSOH (Cintulová \& Altmann, unpublished).

The esterification of alcohol 7 with acid 8 under Yamaguchi conditions [37] at RT furnished diene 6 in moderate but acceptable yields of $44 \%-65 \%$ (Scheme 5).
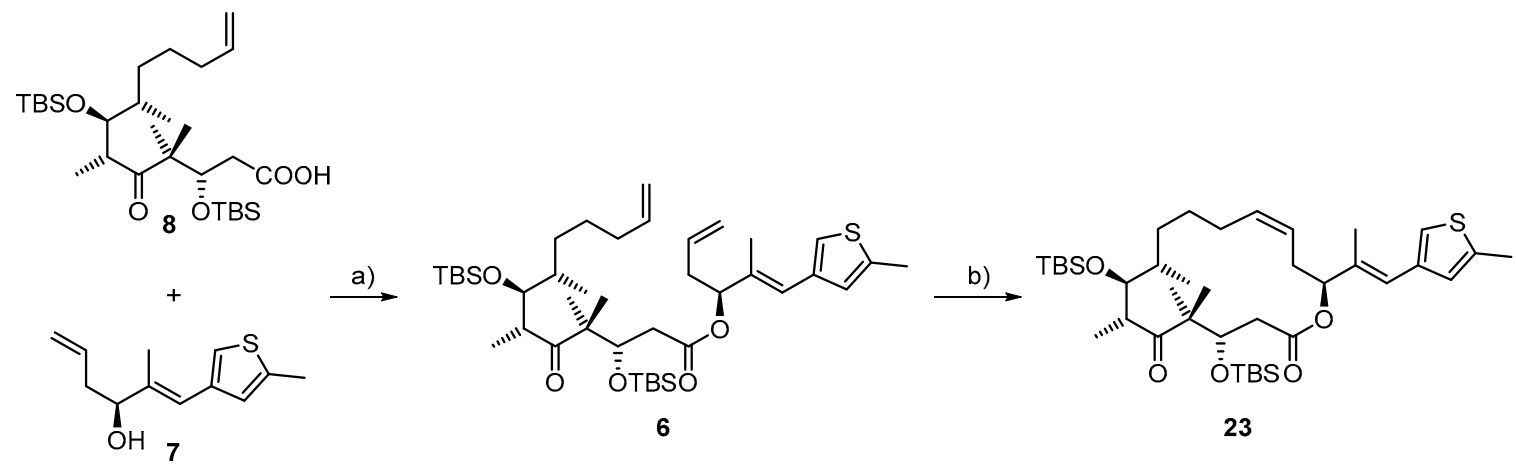

Scheme 5. a) Reagents and conditions: $\mathrm{NEt}_{3}$, 2,4,6-trichlorobenzoyl chloride (TCBC), DMAP, 3 h, RT, $44 \%-65 \%$; b) Grubbs II cat., toluene, $40{ }^{\circ} \mathrm{C}, 17 \%$.

A series of screening experiments was then performed on an analytical scale to identify the best conditions for the crucial ring-closure reaction, including a range of solvents (DCM, benzene, toluene, THF) and different metathesis catalysts (Grubbs I and II, Hoveyda-Grubbs II, Grubbs III) [38]. Not unexpectedly, the reaction under all conditions investigated suffered from low selectivity; low selectivity has also been reported for the RCM of bis-TBS-protected Epo C with the Grubbs I catalyst [29-31]). However, in contrast to the latter, which delivered the E/Z isomeric mixture of macrocycles in high yield, diene 6 appeared to be of limited stability under the reaction conditions and/or to be consumed by alternative reaction pathways. Overall, the screening experiments, unfortunately, did not provide consistent guidance on how to maximize the yield of the desired macrocycle 23 . Ultimately, the reaction was conducted with 0.1 equiv. of Grubbs II catalyst in toluene at $40{ }^{\circ} \mathrm{C}$ and quenched before complete conversion of the starting material. On a $20 \mathrm{mg}$ scale, these conditions provided $3.5 \mathrm{mg}$ of slightly impure $\mathbf{2 3}(17 \%)$ together with $6.9 \mathrm{mg}(33 \%)$ of the corresponding 12,13-E isomer. When the reaction was carried out for $3 \mathrm{~h}$ at reflux, the E isomer of 23 was obtained in $51 \%$ isolated yield.

The difficulties with the RCM of diene $\mathbf{6}$ were then further aggravated by the fact that no conditions could be identified that would have allowed for the clean deprotection of 23 , including conditions that have been employed successfully in the deprotection of bis-TBS-protected Epo C [29-31]. These findings, which point to a distinct instability of $\mathbf{2 3}$ (or 5) compared to (protected) Epo C, called for a change to a protecting group more easily removable than TBS. An obvious candidate that would meet this requirement was the TMS group and we felt that the corresponding acid 8a (Figure 4) could be readily available from $\mathbf{9}$ in analogy to the preparation of $\mathbf{8}$, by simply substituting TMSOTf for TBSOTf. 


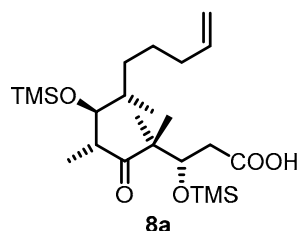

Figure 4. Molecular structures of acid 8a.

Unfortunately, the treatment of $\mathbf{9}$ with TMSOTf under a variety of conditions did not lead to complete conversion to the bis-TMS ether 8a, even if a large excess of TMSOTf was employed (up to 75-fold); in addition, the retro aldol cleavage of the $\mathrm{C} 3-\mathrm{C} 4$ bond was frequently observed as a side reaction [39]. The purification of acid $\mathbf{8 a}$ by silica gel chromatography was possible to some extent, but was complicated by the limited stability of the compound under the chromatographic conditions. In contrast to 8a, mono-TMS-ether $\mathbf{2 6}$ (Scheme 6) could be obtained in 53\% yield after column chromatography, when TMSOTf and 2,6-lutidine were premixed in DCM before the addition of $\mathbf{9}$ to the reaction mixture (Scheme 6). While the use of $\mathbf{2 6}$ presented its own problems in the subsequent esterification step (vide infra), sufficient quantities of this material could be produced to complete the synthesis of the target structure.<smiles>C=CCCC[C@H]1C[C@](C)([C@H](O)CC(=O)O)C(=O)[C@H](C)[C@H]1OCC</smiles>

25<smiles>C=CCCC[C@H]1[C@@H](OC)[C@@H](C)C(=O)[C@](C)([C@@H](O)CC(=O)OC(CC=C)/C(C)=C/c2csc(C)c2)[C@@H]1C</smiles>

26

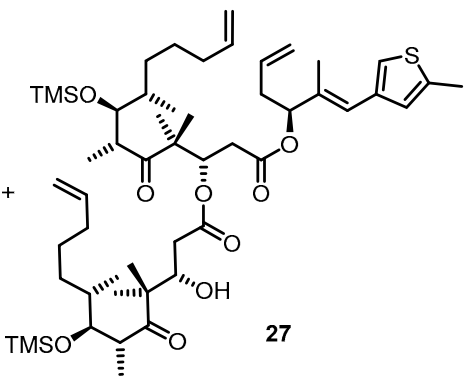

c)<smiles>CC(=Cc1csc(C)c1)C(CC=CCCC[C@@H]1C(O)[C@H](C)C(=O)C1(C)C)OC(=O)CC(C)C</smiles>

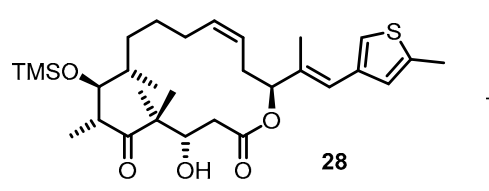

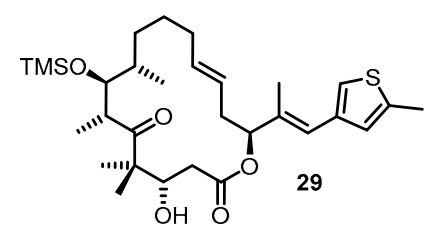

Scheme 6. Reagents and conditions: a) TMSOTf, 2,6-lutidine, DCM, $1.5 \mathrm{~h}, 0{ }^{\circ} \mathrm{C}$ to RT, $53 \%$; b) 7, TCBC, $\mathrm{NEt}_{3}, \mathrm{THF}, \mathrm{DMAP}, 2 \mathrm{~h}, 0{ }^{\circ} \mathrm{C}$ to RT, 39\% for the 2:1 mixture (not separated) of $\mathbf{2 6}(26 \%)$ and $27(13 \%)$; c) Grubbs I cat., toluene, RT, 18 h, 13\% (28) and 19\% (29); d) PPTS, EtOH, $0{ }^{\circ} \mathrm{C}, 90 \mathrm{~min}, 67 \%$.

Thus, the reaction of $\mathbf{2 6}$ with $\mathbf{7}$ under Yamaguchi conditions gave the desired ester $\mathbf{2 6}$ and the dimeric structure 27 [40] in a ca. 2:1 ratio and with an overall yield of 39\%. The separation of $\mathbf{2 6}$ and 27 was possible, if tedious, but was better performed after the RCM step. Intriguingly, two attempts at the Yamaguchi esterification of doubly TMS-protected acid 8a only led to slow decomposition, with alcohol 7 being recovered in almost quantitative yields.

RCM with $60 \mathrm{mg}$ of the 2:1 mixture of $\mathbf{2 6}$ and $\mathbf{2 7}$ with Grubbs I catalyst gave $4.5 \mathrm{mg}$ (13\%) of $Z$-product 28 and $6.6 \mathrm{mg}$ (19\%) of E-isomer 29 after two preparative RP-HPLC runs. Furthermore, $6.9 \mathrm{mg}(19 \%)$ of diene $\mathbf{2 6}$ were recovered; no other products were characterized. The configurational assignment of the C12-C13 double bond in $\mathbf{2 8}$ and $\mathbf{2 9}$ was based on $J$ coupling constants obtained via NMR decoupling experiments. For Z-product 28, a coupling constant of $10.9 \mathrm{~Hz}$ was determined, while E-isomer 29 showed a coupling constant of $15.3 \mathrm{~Hz}$ (see the Supporting Material). With the protected macrocycle in hand, removal of the TMS moiety was then attempted with citric acid (MeOH, RT, $12 \mathrm{~h}$ ), 
as this had proven successful for other TMS-protected epothilone analogs [27]; however, the mass of 5 was not detected in the reaction mixture, and RP-HPLC indicated the formation of multiple products. In contrast, the final deprotection of $\mathbf{2 8}$ with PPTS in EtOH gratifyingly afforded deaza-Epo C (5) in $67 \%$ yield after HPLC purification (Scheme 6).

\subsection{Biochemical and Cellular Assessment}

With deaza-Epo C (5) in hand, we assessed the binding of the compound to cross-linked microtubules at different temperatures in comparison with natural Epo C. As can be seen from the data presented in Table 1, for temperatures up to $35^{\circ} \mathrm{C}$, the binding constant of deaza-Epo C (5) for microtubules is ca. 4-fold to 6-fold lower than that of Epo C, corresponding to a free energy difference $\Delta \Delta \mathrm{G}$ of ca. $0.7 \mathrm{kcal} / \mathrm{mol}$ to $1 \mathrm{kcal} / \mathrm{mol}$. Thus, the loss in binding free energy incurred by the replacement of the thiazole nitrogen in Epo $\mathrm{C}$ by a $\mathrm{CH}$ group is rather modest and appears to be comparable with the loss in binding energy observed upon removal of the epoxide oxygen from Epo A (to form Epo C) (Table 1) or the Epo B $\rightarrow$ Epo $\mathbf{D}$ transformation [41]. The difference appears somewhat less pronounced than for the quinoline-based Epo D analogs $\boldsymbol{o}$-Quin-Epo D and $\boldsymbol{p}$-Quin Epo D (Figure 3), where the difference in binding constants is $>10$-fold; however, the differences are small and should not be overinterpreted. At the same time, the data for the quinoline-based epothilones depicted in Figure 3 suggest that the difference in binding free energy observed here between Epo C and deaza-Epo C (5) can most likely be extrapolated to epothilones A, B and D and their corresponding deaza analogs. For temperatures above $35^{\circ} \mathrm{C}$, a marked drop in the microtubule-binding affinity of deaza-Epo C (5) was observed $\left(\mathrm{K}_{\mathrm{b}}\right.$ of $5 \times 10^{5}$ at $\left.42^{\circ} \mathrm{C}\right)$; the effect is significantly more pronounced than for Epo $\mathrm{C}\left(\mathrm{K}_{\mathrm{b}}\right.$ of $88 \times 10^{5}$ at $42^{\circ} \mathrm{C}$ ). The cause for this behavior is unclear at this point, but may be related to the limited chemical stability of the compound 5 at higher temperatures (vide infra).

Table 1. Binding constants of deaza-Epo C (5), Epo C and Epo A for stabilized microtubules. ${ }^{1}$

\begin{tabular}{|c|c|c|c|}
\hline \multirow[t]{2}{*}{ Compound } & \multicolumn{3}{|c|}{$K_{b}\left[10^{7} M^{-1}\right]$} \\
\hline & $26^{\circ} \mathrm{C}$ & $30^{\circ} \mathrm{C}$ & $35^{\circ} \mathrm{C}$ \\
\hline 5 & $0.39 \pm 0.03$ & $0.33 \pm 0.02$ & $0.37 \pm 0.05$ \\
\hline Epo C & $1.46 \pm 0.33$ & $1.19 \pm 0.15$ & $1.93 \pm 0.27$ \\
\hline Epo A ${ }^{2}$ & $7.48 \pm 1.00$ & $5.81 \pm 1.08$ & $3.63 \pm 0.51$ \\
\hline
\end{tabular}

${ }^{1}$ Association constant $\mathrm{K}_{\mathrm{b}}$ with glutaraldehyde-stabilized microtubules at different temperatures, determined as described in ref. [42]. Numbers are average values from three independent experiments \pm standard deviation.

${ }^{2}$ From ref. [41].

Epothilone analogs with similar Kb's as deaza-Epo C (5) have been reported to exhibit sub- $\mu \mathrm{M}$ antiproliferative activity [26], and it was, therefore, surprising that $\mathbf{5}$ showed no growth inhibition of the human cancer cell lines MCF7 (breast) or A549 (lung) up to a concentration of $10 \mu \mathrm{M}$. In contrast, and as expected from the literature, Epo C inhibited the growth of MCF7 and A549 cells with $\mathrm{IC}_{50}$ values of $9 \mathrm{nM}$ and $103 \mathrm{nM}$, respectively [33]. These findings triggered experiments on the stability of 5 in cell culture medium, which revealed that the compound was degraded with a half-life of less than $2 \mathrm{~h}$; this is significantly lower than the half-life of Epo C under identical conditions (see the Supporting Material). Due to limitations in the sensitivity of the analytical system, the experiments had to be carried out at a $100 \mu \mathrm{M}$ concentration, which is 10 -fold higher than the highest concentration tested in the growth inhibition experiments. While our stability data, thus, are largely qualitative in nature, they do indicate that the limited stability of deaza-Epo C (5) in cell culture medium may contribute to the lack of cellular potency.

\section{Conclusions}

Deaza-epothilone C (5), which incorporates a thiophene heterocycle in place of the thiazole moiety in natural epothilones, has been prepared by semisynthesis from epothilone A. The synthesis 
of building blocks 8 (from epothilone A) and 7 (from 3-thienylmethanol) was accomplished with reasonable efficiency; the synthesis of the alternatively protected acids $8 \mathbf{a}$ and $\mathbf{2 3}$ proved to be more difficult. Likewise, the elaboration of these building blocks into deaza-epothilone $C$ was hampered by significant difficulties, which (partly) reflect distinct differences in the chemical behavior between the thiophene-containing intermediates and their thiazole-derived congeners. As a consequence, deaza-epothilone C (5) was obtained from 7 in only $2.3 \%$ overall yield (three steps). Nevertheless, sufficient material could be procured to assess the binding of 5 to microtubules and its cellular activity. While the replacement of the thiazole nitrogen by a simple $\mathrm{CH}$ group causes a drop in the the free energy of binding of 5 relative to epothilone $C$, in agreement with structural data for the tubulin/Epo A complex and also previous (binding) data for quinoline-based epothilone analogs, the magnitude of the decrease (between 0.7 and $1 \mathrm{kcal} / \mathrm{mol}$ ) is rather modest. Thus, the data indicate that, in principle, thiophene-derived analogs of epothilone A or B (or macrocycle-modified variants thereof) should be high-affinity microtubule binders. However, high-affinity microtubule-binding of such analogs may not translate into potent cellular activity, as indicated by the reduced stability (compared to epothilone C) and lack of cellular activity observed for deaza-epothilone C (5). At the same time, stability may be enhanced by appropriate modification of the thiophene ring (e.g., by the replacement of the methyl group by a quasi-isosteric electron-withdrawing chlorine atom). These questions will have to be clarified in future experiments.

Supplementary Materials: The following are available online at http://www.mdpi.com/2624-8549/2/2/30/s1, synthesis protocols and analytical data for all new compounds, Figure S1: Decoupling experiments with 28, Figure S2: Decoupling experiments with 29, Figure S3: Stability of deaza-Epo C (5) in Dulbecco's Modified Eagle Medium (DMEM) over a $2 \mathrm{~h}$ time period, Figure S4: Stability of deaza-Epo C (5) in DMEM over a $24 \mathrm{~h}$ time period, Figure S5: Stability of Epo C in DMEM over a $2 \mathrm{~h}$ time period, Figure S6: Stability of Epo C in DMEM over a $24 \mathrm{~h}$ time period.

Author Contributions: Conceptualization, K.-H.A.; methodology, K.-H.A., A.E., J.F.D.; formal analysis, A.E., K.-H.A., J.F.D.; investigation, A.E., L.R., D.C., J.E.-G.; data curation, A.E., J.E.-G.; writing, K.-H.A.; supervision, K.-H.A.; funding acquisition, J.F.D. All authors have read and agreed to the published version of the manuscript.

Funding: This work was supported by institutional funding from ETH Zürich (A.E., K.-H.A., L.R., D.C.) and by Ministerio de Economia y Competitividad grants BFU2016-75319-R to J.F.D. (both AEI/FEDER, UE) and H2020-MSCA-ITN-2019 860070 TUBINTRAIN to J.F.D. and a donation from Club deportivo Escuela Hungaresa de Pontevedra. No funds were received to cover the costs for publication in open access.

Acknowledgments: The authors acknowledge networking contributions by the COST Action CM1407 "Challenging organic syntheses inspired by nature - from natural products chemistry to drug discovery". We are indebted to Bernhard Pfeiffer (ETHZ) for NMR support, and to Xiangyang Zhang, Louis Bertschi, Rolf Häfliger and Oswald Greter (ETHZ) for HRMS spectra. Kurt Hauenstein is acknowledged for excellent technical assistance.

Conflicts of Interest: The authors declare no conflict of interest.

\section{References and Notes}

1. Gerth, K.; Bedorf, N.; Höfle, G.; Irschik, H.; Reichenbach, H. Epothilons A and B: Antifungal and Cytotoxic Compounds from Sorangium cellulosum (Myxobacteria). Production, Physico-chemical and Biological Properties. J. Antibiot. 1996, 49, 560-563. [CrossRef]

2. Höfle, G.; Reichenbach, H. Epothilone, a myxobacterial metabolite with promising antitumor activity. In Anticancer Agents from Natural Products; Cragg, G.M., Kingston, D.G.I., Newman, D.J., Eds.; Taylor \& Francis: Boca Raton, FL, USA, 2005; pp. 413-450. [CrossRef]

3. Hardt, I.H.; Steinmetz, H.; Gerth, K.; Sasse, F.; Reichenbach, H.; Höfle, G. New Natural Epothilones from Sorangium cellulosum, Strains So ce90/B2 and So ce90/D13: Isolation, Structure Elucidation, and SAR Studies. J. Nat. Prod. 2001, 64, 847-856. [CrossRef] [PubMed]

4. Höfle, G.H.; Bedorf, N.; Steinmetz, H.; Schomburg, D.; Gerth, K.; Reichenbach, H. Antibiotics from gliding bacteria. 77. Epothilone A and B-novel 16-membered macrolides with cytotoxic activity: Isolation, crystal structure, and conformation in solution. Angew. Chem. Int. Ed. 1996, 35, 1567-1569. [CrossRef] 
5. Bollag, D.M.; McQueney, P.A.; Zhu, J.; Hensens, O.; Koupal, L.; Liesch, J.; Goetz, M.; Lazarides, E.; Woods, C.M. Epothilones, a new class of microtubule-stabilizing agents with a Taxol-like mechanism of action. Cancer Res. 1995, 55, 2325-2333.

6. Kowalski, R.J.; Giannakakou, P.; Hamel, E. Activities of the microtubule-stabilizing agents epothilones A and B with purified tubulin and in cells resistant to paclitaxel (Taxol). J. Biol. Chem. 1997, 272, 2534-2541. [CrossRef] [PubMed]

7. Altmann, K.-H.; Wartmann, M.; O'Reilly, T. Epothilones and related structures-a new class of microtubule inhibitors with potent in vivo antitumor activity. Biochim. Biophys. Acta 2000, 1470, M79-M91. [CrossRef]

8. Nicolaou, K.C.; Roschangar, F.; Vourloumis, D. Chemical Biology of Epothilones. Angew. Chem. Int. Ed. 1998, 37, 2014-2045. [CrossRef]

9. Harris, C.R.; Danishefsky, S.J. Complex target-oriented synthesis in the drug discovery process: A case history in the dEpoB series. J. Org. Chem. 1999, 64, 8434-8456. [CrossRef]

10. Nicolaou, K.C.; Ritzén, A.; Namoto, K. Recent developments in the chemistry, biology and medicine of the epothilones. Chem. Commun. 2001, 1523-1535. [CrossRef]

11. Altmann, K.-H. The merger of natural product synthesis and medicinal chemistry: On the chemistry and chemical biology of epothilones. Org. Biomol. Chem. 2004, 2, 2137-2151. [CrossRef]

12. Watkins, E.B.; Chittiboyina, A.G.; Avery, M.A. Recent Developments in the Syntheses of the Epothilones and Related Analogues. Eur. J. Org. Chem. 2006, 4071-4084. [CrossRef]

13. Nicolaou, K.C. The Chemistry-Biology-Medicine Continuum and the Drug Discovery and Development Process in Academia. Chem. Biol. 2014, 21, 1039-1045. [CrossRef] [PubMed]

14. Altmann, K.-H.; Pfeiffer, B.; Arseniyadis, S.; Pratt, B.A.; Nicolaou, K.C. The chemistry and biology of epothilones-The wheel keeps turning. ChemMedChem 2007, 2, 397-423. [CrossRef] [PubMed]

15. Altmann, K.H.; Kinghorn, A.D.; Höfle, G.; Müller, R.; Prantz, K. For a Book on Epothilones cf.: The Epothilones: An Outstanding Family of Anti-Tumor Agents (Progress Chem. Org. Nat. Prod. 90); Kinghorn, A.D., Falk, H., Kobayashi, J., Eds.; Springer Wien: New York, NY, USA, 2009; ISBN 978-3-211-78207-1. [CrossRef]

16. Altmann, K.-H.; Gaugaz, F.Z.; Schiess, R. Diversity through semisynthesis: The chemistry and biological activity of semisynthetic epothilone derivatives. Mol. Divers. 2011, 15, 383-399. [CrossRef] [PubMed]

17. Lechleider, R.J.; Kaminskas, E.; Jiang, X.; Aziz, R.; Bullock, J.; Kasliwal, R.; Harapanhalli, R.; Pope, S.; Sridhara, R.; Leighton, J.; et al. Ixabepilone in Combination with Capecitabine and as Monotherapy for Treatment of Advanced Breast Cancer Refractory to Previous Chemotherapies. Clin. Cancer Res. 2008, 14, 4378-4384. [CrossRef]

18. Barten, D.M.; Fanara, P.; Andorfer, C.; Hoque, N.; Wong, P.Y.A.; Husted, K.H.; Cadelina, G.W.; DeCarr, L.B.; Yang, L.; Liu, V.; et al. Hyperdynamic microtubules, cognitive deficits, and pathology are improved in tau transgenic mice with low doses of the microtubule-stabilizing agent BMS-241027. J. Neurosci. 2012, 32, 7137-7145. [CrossRef]

19. Zhang, P.; Sun, T.; Zhang, Q.; Yuan, Z.; Jiang, Z.; Wang, X.J.; Cui, S.; Teng, Y.; Hu, X.-C.; Yang, J.; et al. Utidelone plus capecitabine versus capecitabine alone for heavily pretreated metastatic breast cancer refractory to anthracyclines and taxanes: A multicentre, open-label, superiority, phase 3, randomised controlled trial. Lancet Oncol. 2017, 18, 371-383. [CrossRef]

20. Nicolaou, K.C.; Scarpelli, R.; Bollbuck, B.; Werschkun, B.; Pereira, M.M.A.; Wartmann, M.; Altmann, K.-H.; Zaharevitz, D.; Gussio, R.; Giannakakou, P. Chemical synthesis and biological properties of pyridine epothilones. Chem. Biol. 2000, 7, 593-599. [CrossRef]

21. Su, D.-S.; Meng, D.; Bertinato, P.; Balog, A.; Sorensen, E.J.; Danishefsky, S.J.; Zheng, Y.-H.; Chou, T.C.; He, L.; Horwitz, S.B. Total synthesis of (-)-epothilone B: An extension of the Suzuki coupling method and insights into structure-activity relationships of the epothilones. Angew. Chem. Int. Ed. 1997, 37, 757-759. [CrossRef]

22. Dietrich, S.; Lindauer, R.; Stierlin, C.; Gertsch, J.; Matesanz, R.; Notararigo, S.; Díaz, J.F.; Altmann, K.-H. Epothilone Analogs with Benzimidazole and Quinoline Side Chains: Chemical Synthesis, Antiproliferative Activity, and Interactions with Tubulin. Chem. Eur. J. 2009, 15, 10144-10157. [CrossRef]

23. Prota, A.E.; Bargsten, K.; Zurwerra, D.; Field, J.J.; Díaz, J.F.; Altmann, K.-H.; Steinmetz, M.O. Molecular Mechanism of Action of Microtubule-Stabilizing Anticancer Agents. Science 2013, 339, 587-590. [CrossRef]

24. Sefkow, M.; Kiffe, M.; Schummer, D.; Höfle, G. Oxidative and reductive transformations of epothilone A. Bioorg. Med. Chem. Lett. 1998, 8, 3025-3030. [CrossRef] 
25. Höfle, G.; Glaser, N.; Leibold, T.; Karama, U.; Sasse, F.; Steinmetz, H. Semisynthesis and degradation of the tubulin inhibitors epothilone and tubulysin. Pure Appl. Chem. 2003, 75, 167-178. [CrossRef]

26. Erdélyi, M.; Navarro-Vázquez, A.; Pfeiffer, B.; Kuzniewski, C.N.; Felser, A.; Widmer, T.; Gertsch, J.; Pera, B.; Díaz, J.F.; Altmann, K.-H.; et al. The binding mode of side chain- and C3-modified epothilones to tubulin. ChemMedChem 2010, 5, 911-920. [CrossRef]

27. Schiess, R.; Gertsch, J.; Schweizer, W.B.; Altmann, K.-H. Stereoselective Synthesis of 12,13-Cyclopropyl-Epothilone B and Side-Chain-Modified Variants. Org. Lett. 2011, 13, 1436-1439. [CrossRef]

28. Karama, U.; Höfle, G. Synthesis of epothilone 16,17-alkyne analogs by replacement of the C13-C15(O)-ring segment of natural epothilone C. Eur. J. Org. Chem. 2003, 1042-1049. [CrossRef]

29. Schinzer, D.; Limberg, A.; Bauer, A.; Böhm, O.M.; Cordes, M. Total synthesis of (-)-epothilone A. Angew. Chem. Int. Ed. Engl. 1997, 36, 523-524. [CrossRef]

30. Nicolaou, K.C.; He, Y.; Vourloumis, D.; Vallberg, H.; Zang, Z. Total synthesis of epothilone A: The olefin metathesis approach. Angew. Chem. Int. Ed. Engl. 1997, 36, 166-168. [CrossRef]

31. Balog, A.; Meng, D.; Kamenecka, T.; Bertinato, P.; Su, D.S.; Sorensen, E.J.; Danishefsky, S.J. Total synthesis of (-)-epothilone A. Angew. Chem. Int. Ed. Engl. 1996, 35, 2801-2803. [CrossRef]

32. Nicolaou, K.C.; He, Y.; Vourloumis, D.; Vallberg, H.; Roschangar, F.; Sarabia, F.; Ninkovic, S.; Yang, Z.; Trujillo, J.I. The Olefin Metathesis Approach to Epothilone A and Its Analogs. J. Am. Chem. Soc. 1997, 119, 7960-7973. [CrossRef]

33. Altmann, K.-H.; Flörsheimer, A.; Bold, G.; Caravatti, G.; End, N.; Wartmann, M. Natural product-based drug discovery-Epothilones as lead structures for the development of new anticancer agents. Chimia 2004, 58, 686-690. [CrossRef]

34. Calo, V.; Lopez, L.; Mincuzzi, A.; Pesce, G. 3-Methyl-2-selenoxobenzothiazole, a New Reagent for the Stereospecific Deoxygenation of Epoxides and the Desulfurization of Episulfides into Olefins. Synthesis 1976, 200-201. [CrossRef]

35. Bond, S.; Perlmutter, P. N-Acetylbornane-10,2-sultam: A Useful, Enantiomerically Pure Acetate Synthon for Asymmetric Aldol Reactions. J. Org. Chem. 1997, 62, 6397-6400. [CrossRef]

36. The (S)-configuration of the major isomer is inferred from the known stereochemical outcome of acetate aldol reactions with $\mathrm{N}$-acetylbornane-10,2-sultam 18 related (see refs. [22,35]).

37. Inanaga, J.; Hirata, K.; Saeki, H.; Katsuki, T.; Yamaguchi, M. A Rapid Esterification by Means of Mixed Anhydride and Its Application to Large-ring Lactonization. Bull. Chem. Soc. Jpn. 1979, 52, 1989-1993. [CrossRef]

38. Lecourt, C.; Dhambri, S.; Allievi, L.; Sanogo, Y.; Zeghbib, N.; Ben Othman, R.; Lannou, M.-I.; Sorin, G.; Ardisson, J. Natural products and ring-closing metathesis: Synthesis of sterically congested olefins. Nat. Prod. Rep. 2018, 35, 105-124. [CrossRef]

39. Niggemann, J.; Michaelis, K.; Frank, R.; Zander, N.; Höfle, G. Natural product-derived building blocks for combinatorial synthesis. Part 1. Fragmentation of natural products from myxobacteria. J. Chem. Soc. Perkin Trans. 1 2002, 2490-2503. [CrossRef]

40. The structural assignment of $\mathbf{2 7}$ is tentatively based on ${ }^{1} \mathrm{H}-\mathrm{NMR}$ analysis and MS.

41. Buey, R.M.; Díaz, J.F.; Andreu, J.M.; O’Brate, A.; Giannakakou, P.; Nicolaou, K.C.; Sasmal, P.K.; Ritzén, A.; Namoto, K. Interaction of Epothilone Analogs with the Paclitaxel Binding Site: Relationship between Binding Affinity, Microtubule Stabilization, and Cytotoxicity. Chem. Biol. 2004, 11, 225-236. [CrossRef]

42. Matesanz, R.; Barasoain, I.; Yang, C.; Wang, L.; Li, X.; De Ines, C.; Coderch, C.; Gago, F.; Jiménez-Barbero, J.; Andreu, J.M.; et al. Optimization of taxane binding to microtubules. Binding affinity dissection and incremental construction of a high-affinity analogue of paclitaxel. Chem. Biol. 2008, 15, 573-585. [CrossRef]

(C) 2020 by the authors. Licensee MDPI, Basel, Switzerland. This article is an open access article distributed under the terms and conditions of the Creative Commons Attribution (CC BY) license (http://creativecommons.org/licenses/by/4.0/). 